\title{
Comparative influence analysis of various tropical cyclones in the South China Sea on the structure of the Vietnamese Current
}

\author{
Galina Vlasova ${ }^{1}$, Xuan Ba Nguyen ${ }^{2}$, and Thuy Dung Thi Nguyen ${ }^{2}$ \\ Received 16 February 2020; accepted 18 April 2020; published 7 August 2020.
}

We analyze the water circulation in the zone of the Vietnamese Current in the South China Sea, which is the Western Boundary of the area. We use numerical modeling and calculate the full flow equations in the spring of 1999, what is a transition period from winter to summer. The main goal of the work is a comparative analysis of the influence of various tropical cyclones of the South China Sea on the vertical structure of the Vietnamese Current. We compare the trajectories of the tropical cyclones located in the northern and southern parts of the sea influenced differently at the circulation in the basin. We demonstrate that the tropical cyclones in the southern (northern) parts of the China Sea intensify significantly the Vietnamese Current. This causes the summer type of water transport from south to north named the summer regime of the Vietnamese Current while the other part of the area remains under the influence of the winter regime of water transport with the current propagating from north to south. KEYWORDS: South China Sea; Vietnamese Current (Western boundary); atmospheric processes; water circulation; cyclone; anticyclone; hydrodynamic structures; numerical modeling.

Citation: Vlasova, Galina, Xuan Ba Nguyen, and Thuy Dung Thi Nguyen (2020), Comparative influence analysis of various tropical cyclones in the South China Sea on the structure of the Vietnamese Current, Russ. J. Earth. Sci., 20, ES5001, doi:10.2205/2020ES000716.

\section{Introduction}

The article continues the original studies to reveal the influence of regional atmospheric circulation on hydrodynamic processes in the western part of the South China Sea where the Vietnamese Current dominates (Figure 1). A first researcher who discovered the connection of the water circulation in the region with cyclones was Wirtki [Wyrtki,

\footnotetext{
${ }^{1}$ Il'ichev Pacific Oceanological Institute, Far Eastern Branch RAS, Vladivostok, Russia

${ }^{2}$ Institute of Oceanography, Vietnamese Academy of Science and Technology (IO VAST), Nha Trang, Vietnam
}

Copyright 2020 by the Geophysical Center RAS. http://rjes.wdcb.ru/doi/2020ES000716-res.html
1961. He established the existence of a strong coastal jet, propagating along the Vietnam coastline, called the Vietnamese Current. The main feature of the Vietnamese Current is a change in its direction under the influence of the monsoon (see Figure 1).

The authors of this study carried out a series of similar researches to find out how the hydrodynamic regime of the coastal waters of the Vietnamese Current is influenced with the conditions of the only monsoon as the dominant factor in the absence of tropical cyclones [Vlasova et al., 2011, 2012, 2013a, 2018. Besides, they provided an analysis of the restructuring of the hydrodynamic regime under the influence of tropical cyclones located in the southern part of the South China Sea as well as the north part [Vlasova et al., 2013b. 

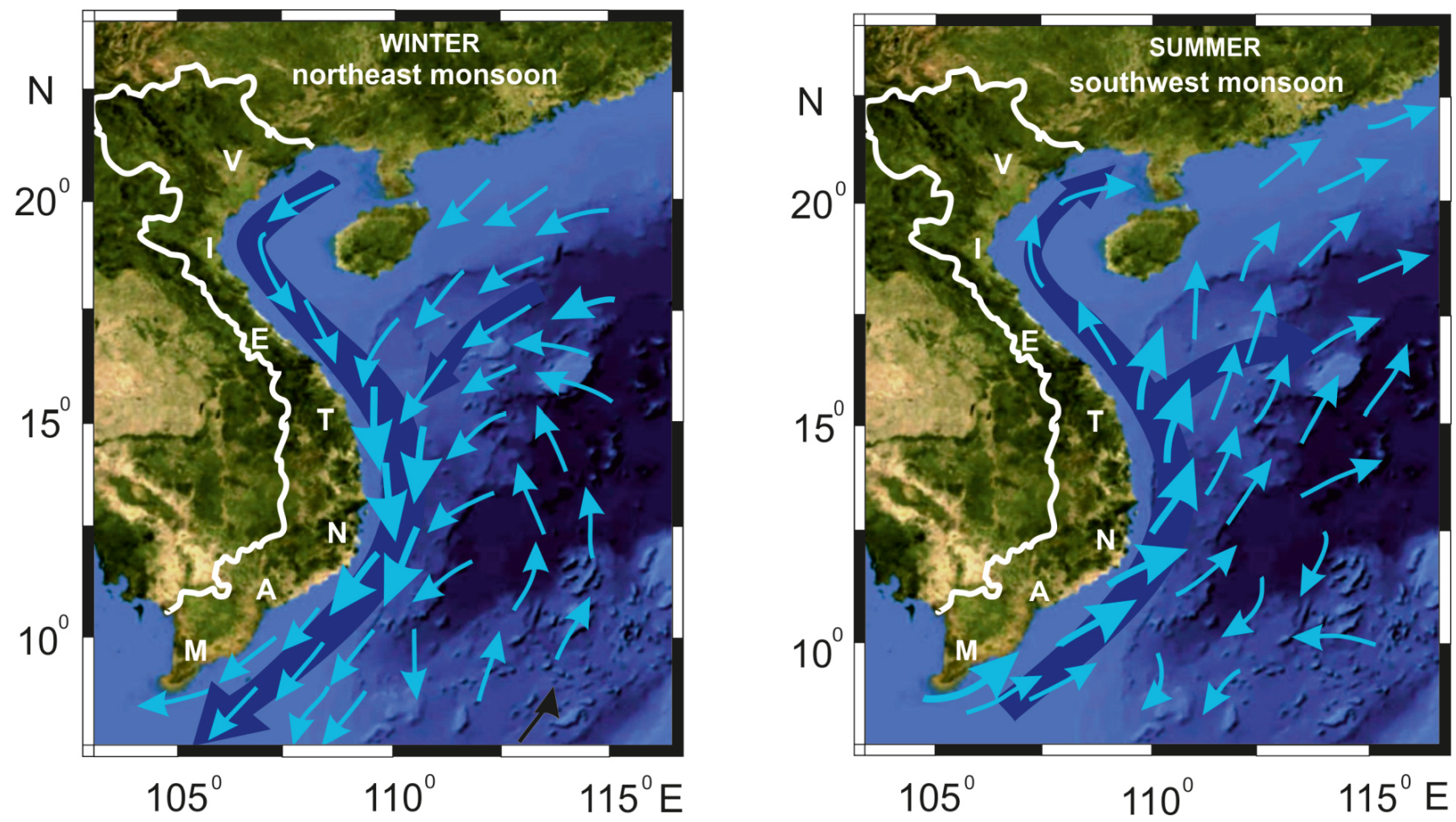

Figure 1. Large dark blue arrow indicates the Vietnamese Current in the South China

Sea, small blue arrows indicate the Wyrtki current [ Wyrtki, 1961].

2016a. The authors also derived a comparative analysis of the effect on the hydrodynamic situation of monsoons and tropical cyclones located in the south of the South China Sea [Vlasova et al., $2016 \mathrm{~b}$.

This article is devoted to a comparative analysis of the influence of tropical cyclones located in the northern or southern parts of the South China Sea on changes in the hydrodynamic regime and water structure in the coastal region of Vietnam.

The general state of the environment of the South China Sea and its continental and island surroundings substantially depends on regional synoptic processes (seasonal monsoons, trade-winds, tropical cyclones). They also affect the intensity of the hydrodynamic processes, restructuring of the Sea currents and their spatial and temporal variability.

Due to the influence of monsoons, in the conditions surrounding the mountainous terrain, the spatial-temporal structure of the currents has its characteristics. A vivid example of this is the Vietnamese current [Dang, 1974, Liu et al., 2008, Morimoto et al., 2000, Siripong, 1985, Tang et al., 2004. Qu, 2000, Vlasova et al., 2010, Wyrtki, 1961; and et al.] (see Figure 1). In winter, under the influence of the northeastern monsoon, it is directed from north to south, as a result of which a cyclonic water circulation forms. In summer, with the southwestern monsoon, this current is directed in the opposite direction forming an anticyclonic circulation of water along the eastern coast of Vietnam. The indicated hydrodynamics changes significantly if a tropical cyclone occurs above the South China Sea.

It is known that tropical cyclones originate in the western sector of the Pacific Ocean (Figure 2) and partly in the South China Sea (Figure 3) [Dobryshman, 1980, Kuzin, 1999, Mamedov, 1974. Polyakova, 2011; Zhao et al., 2008, and et al.].

A significant number of cyclones that form in the Pacific Ocean comes into the South China Sea. Together with similar local processes, they lead to changes in the hydrodynamics of the region under consideration. Moreover, moving to the north and northeast tropical cyclones significantly affect the weather and climate of all East Asia including the Russian Far East [Barabashkina and Leskova, 1968. Domysheva, 2019, Kuznetsov, 1997; and et al.]. The hydrodynamics of the northwestern part of the Pacific Ocean and its marginal seas are also affected by these extreme synoptic processes. It defines the need for the study of hydrodynamic 


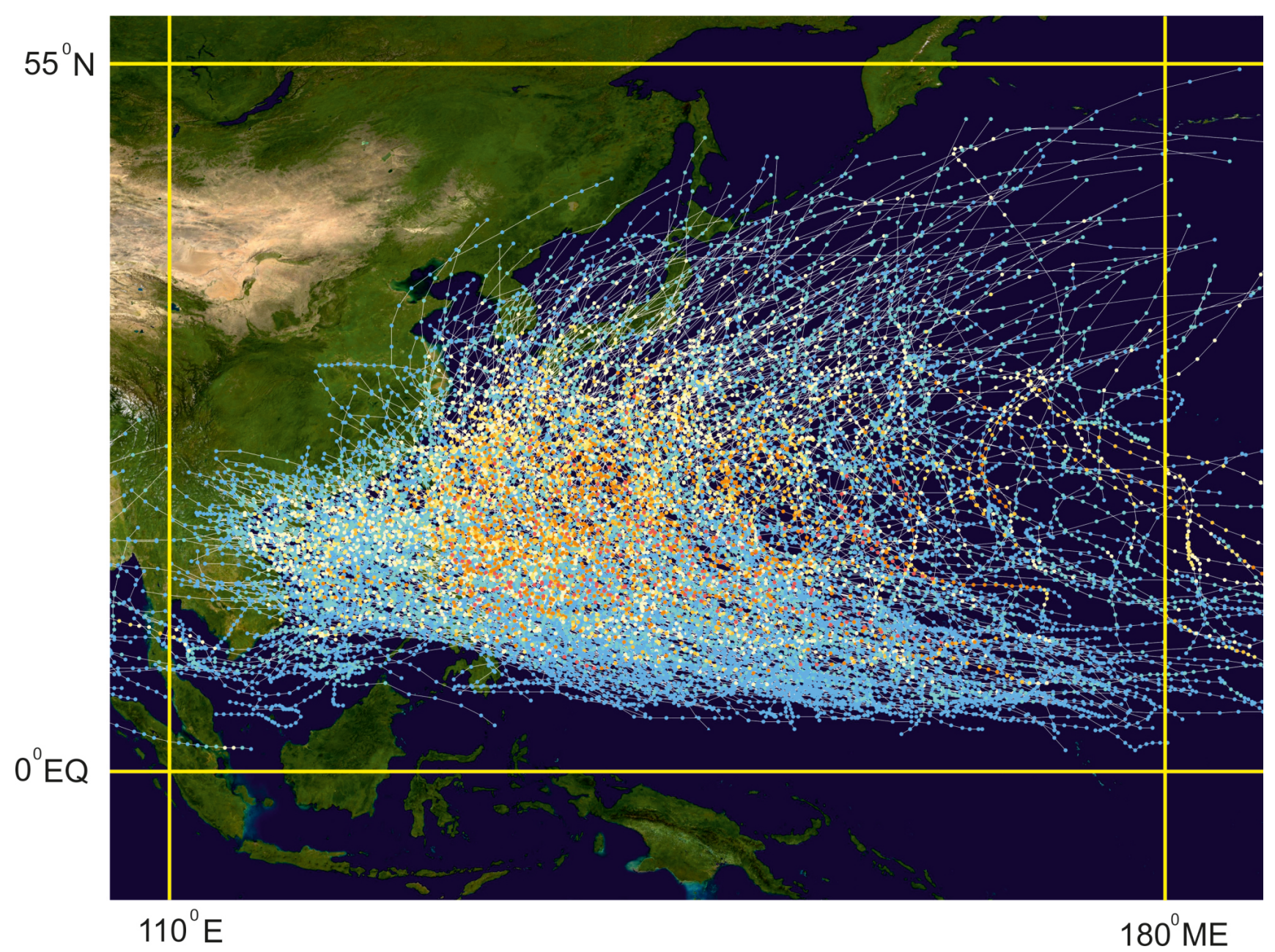

Figure 2. The trajectories of tropical cyclones over the northwest Pacific for the period 1980-2005 (author: Nilfanion - Created using WikiProject Tropical cyclones/Tracks. The background image is from NASA (https://en.wikipedia.org/wiki/NASA). The tracking data is from the Joint Typhoon Warning Center's best track database, public domain, (https://commons.wikimedia.org/w/index.php?curid=1724639).

and synoptic processes of the South China Sea as a trans-regional scale phenomenon.

The influence of a tropical cyclone on the hydrodynamics of the South China Sea is different if its center is located above the northern or southern part of this sea. This phenomenon has become the subject of our research.

The purpose of this article is to study changes in the vertical structure of the Vietnamese Current under the influence of a tropical cyclone located in the northern and southern parts of the South China Sea. This study is based on numerical modeling. As the estimated season, spring 1999 was used. During this period, the Southeast Asian and Japanese Fisheries Association carried out an expedition in the area with the participation of
Vietnamese scientists (SEAFDEC, Cruise No. 57$3 / 99$ ). The results of this expedition were provided to us by Vietnamese co-authors and used in the modeling process. Spring is selected as the transition period from winter to summer. The study area is limited by coordinates: $11-16^{\circ} \mathrm{N}$ and 108 $112^{\circ} 30^{\prime} \mathrm{E}$.

\section{Data and Methods}

To solve these problems, a known quasigeostrophic model of water circulation was used [Felsenbaum, 1970, Shapiro, 1965, Vasiliev, 2001, and et al.]. This model has been repeatedly described in 


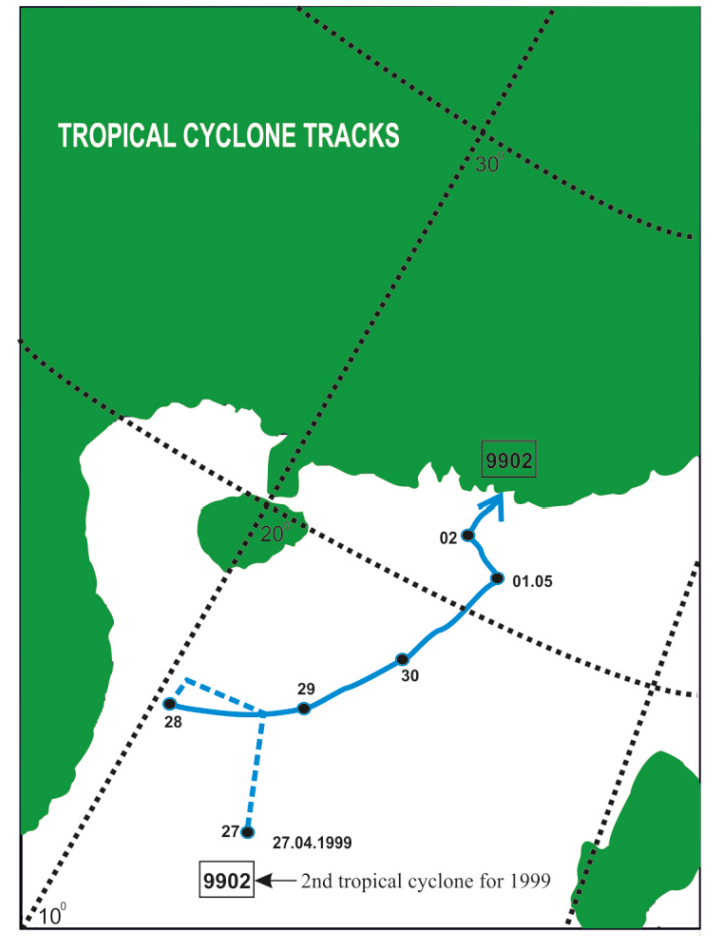

a

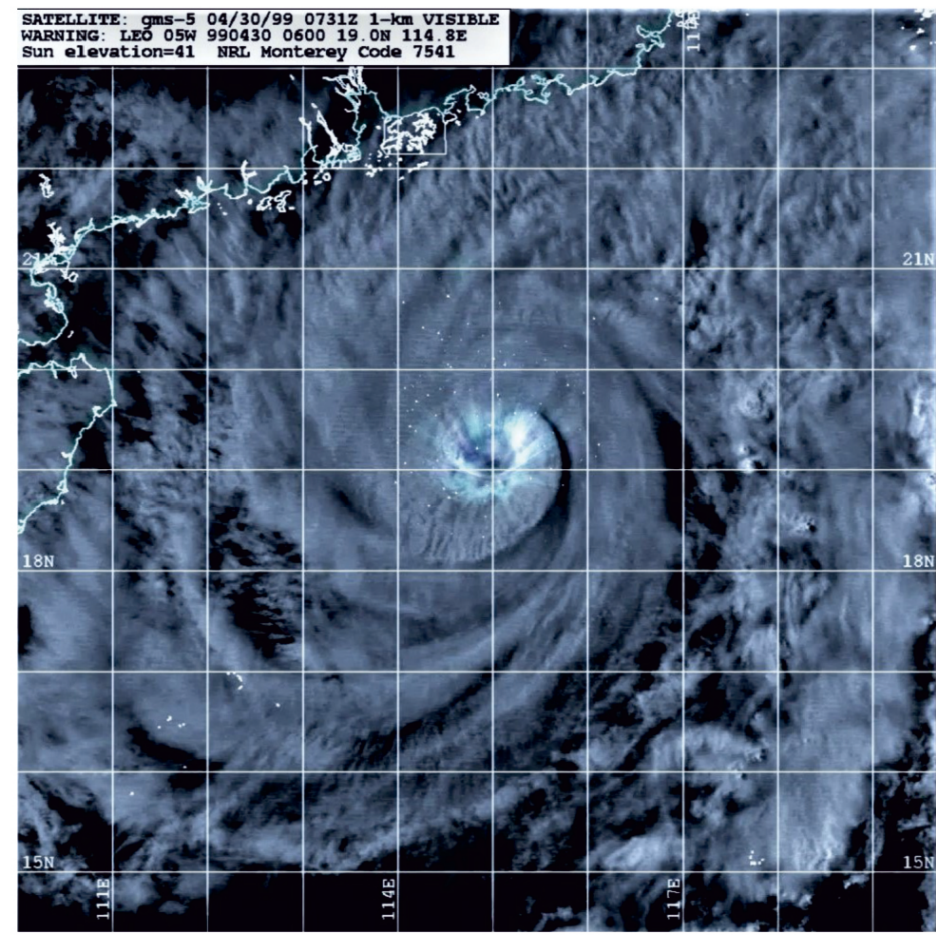

b

Figure 3. The trajectory of the tropical LEO cyclone originating over the water area of the South China Sea (a, http://www.jma.go.jp/jma/jma-eng/jmacenter/rsmc-hp-pub-eg/bstve_1999_m.html, ID = 9902) and reaching its northern part (b, https://coast.noaa.gov/hurricanes//in April 1999.

monographs and articles [Polyakova et al., 2002 . Vasiliev et al., 2011, Vlasova et al., 2008, 2016a, 2016b; and et al.], so here we are limited to its main characteristics.

The model allows calculating the integral circulation of water in the form of a field of total flows $\left(S_{x}=-\partial \psi / \partial y, S_{y}=\partial \psi / \partial x\right)$ by the tangential wind stress $(T)$ and the density of water $\left(\rho^{0}\right)$ on the sea surface. The calculation of the currents structure and the density of water masses for given parameters $T$ and $\rho^{0}$ leads to the solution of the equation for the integral current function $\psi(x, y)$ using the minimal discrepancy method. The function $\psi$ applied on solid boundaries of the water area (coastline), and its normal derivative applied on the liquid boundary.

The model takes into account the vertical distribution of water density, bottom relief, coast orography and the state of the atmosphere over the studied area. Water consumption was determined based on of the calculation of the total flows normal to the liquid boundaries of the studied area.

Within the framework of this model, the inte- gral functions of the current for the surface layer, layer from 0-200 $\mathrm{m}$ and entire water column were calculated.

To take into account atmospheric processes over the South China Sea, their classification was used, which was presented in [Polyakova, 2011]. Two types of atmospheric circulation were used in our work, when tropical cyclones are located in the northern and southern parts of the South China Sea (Figure 4).

The following initial information was used for modeling:

- the contour of the coastline, taken from a hydrographic map and close to its real form;

- values of bottom depths ETOPO-5 (https:// www.ngdc.noaa.gov/mgg/global/eto po5.HTML);

- values of temperature and salinity on the sea surface for the period of 21.04-05.06.1999, according to the expedition of the Fishing Association of Southeast Asia and Japan (SEAFDEC, Cruise No. 57-3/99); 

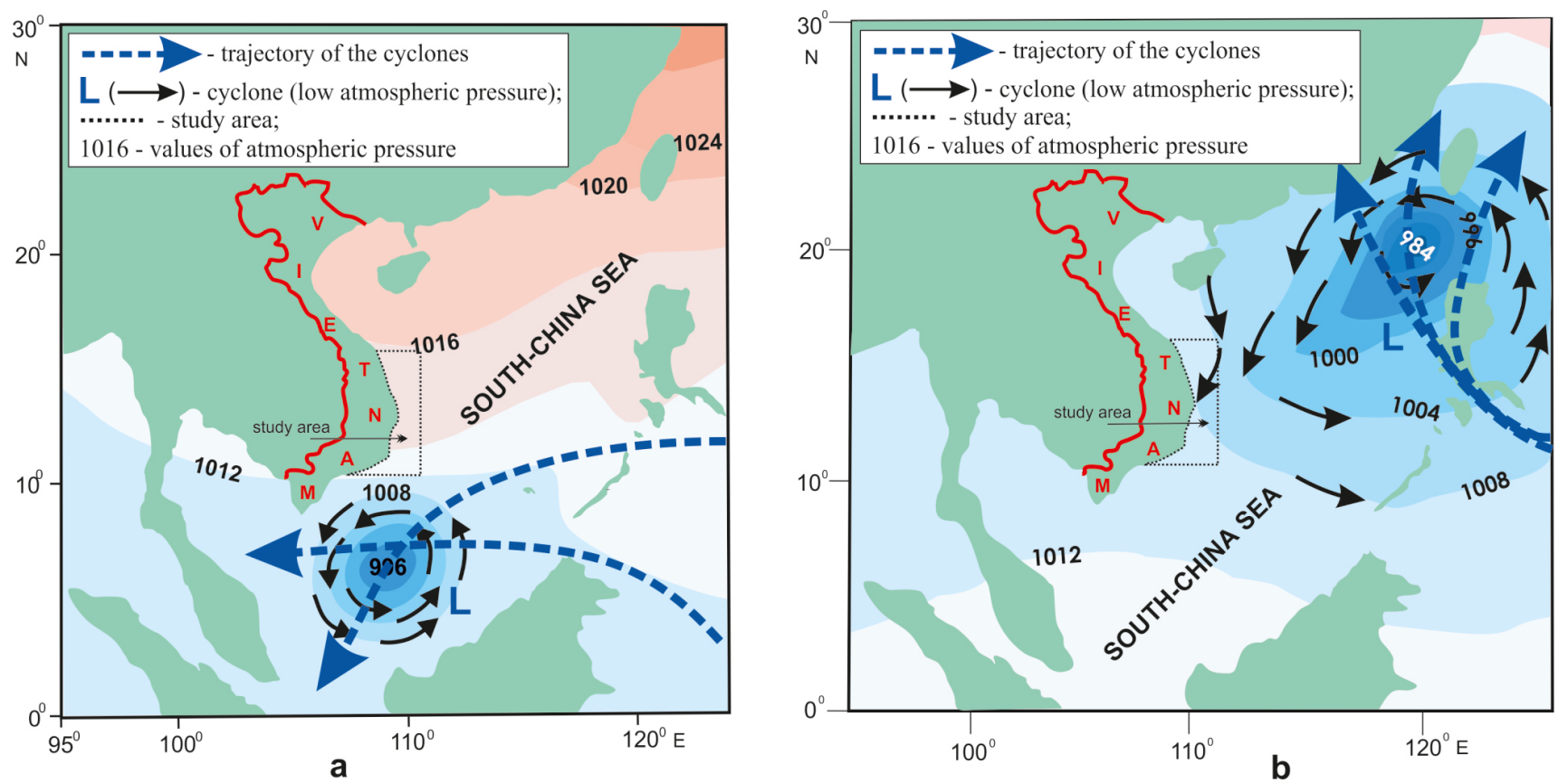

Figure 4. Southern (a) and northern (b) tropical atmospheric cyclones over the South China Sea (data of Polyakova [Polyakova, 2011] was used to build Figure 4).

- values of atmospheric pressure according to the daily synoptic maps of surface atmospheric pressure fields of the Japan Meteorological Agency for the period 2000-2008.

The adhesion conditions were adopted for the bottom (the flow velocity at the bottom is zero). The uniform grid $30^{\prime} \times 30^{\prime}$ was used for calculations under the data provided by Vietnamese co-authors.

Based on the calculation results, water circulation maps were constructed for the surface, layer 0-200 $\mathrm{m}$ and the entire water column (from the surface to the bottom).

\section{Results and Discussion}

Under previous studies, April is a transitional period when currents caused by the winter monsoon persist in the area under consideration, and the winter regime of water dynamics continues. However, the power of the northern stream of water is gradually weakening. In May, south, southwest winds prevail almost over the entire water area. Since that time, the summer regime of hydrodynamics begins [Nguyen, 1990, Uda and Nakao, 1973. Wyrtki, 1961; Yuan et al., 2007, and et al.].
However, our calculations showed that in this period another hydrodynamic situation should be observed here, which differs from that described above. First, the Vietnamese Current, regardless of atmospheric circulation conditions, does not exist in the form of a single and inextricable flow of water masses. Instead, several hydrodynamic cycles are formed: cyclonic and anticyclonic (Figure 5).

Under the influence of the atmospheric tropical cyclone located in the south of the South China Sea, two anticyclonic water cycles are formed on the sea surface separated by a cyclonic cycle. One powerful anticyclonic cycle formed in the north of the study area, the second, much less powerful cycle, is located in the south. The northern anticyclonic cycle collapses with depth. At a depth of 200 meters, it is converted into a vortex which disappears hereinafter. The southern anticyclonic cycle, on the contrary, persists in the entire water column, from the surface to the bottom. The cyclonic cycle expands with depth (see Figure 5a, b, c).

If the atmospheric tropical cyclone is located in the northern half of the South China Sea, two hydrodynamic structures are formed here: powerful anticyclonic and deep cyclonic cycles (see Figure $5 \mathrm{~d}, \mathrm{e}, \mathrm{f})$. These structures extend to the entire water column, from the surface layer to the bottom. Moreover, the anticyclonic cycle at all hori- 

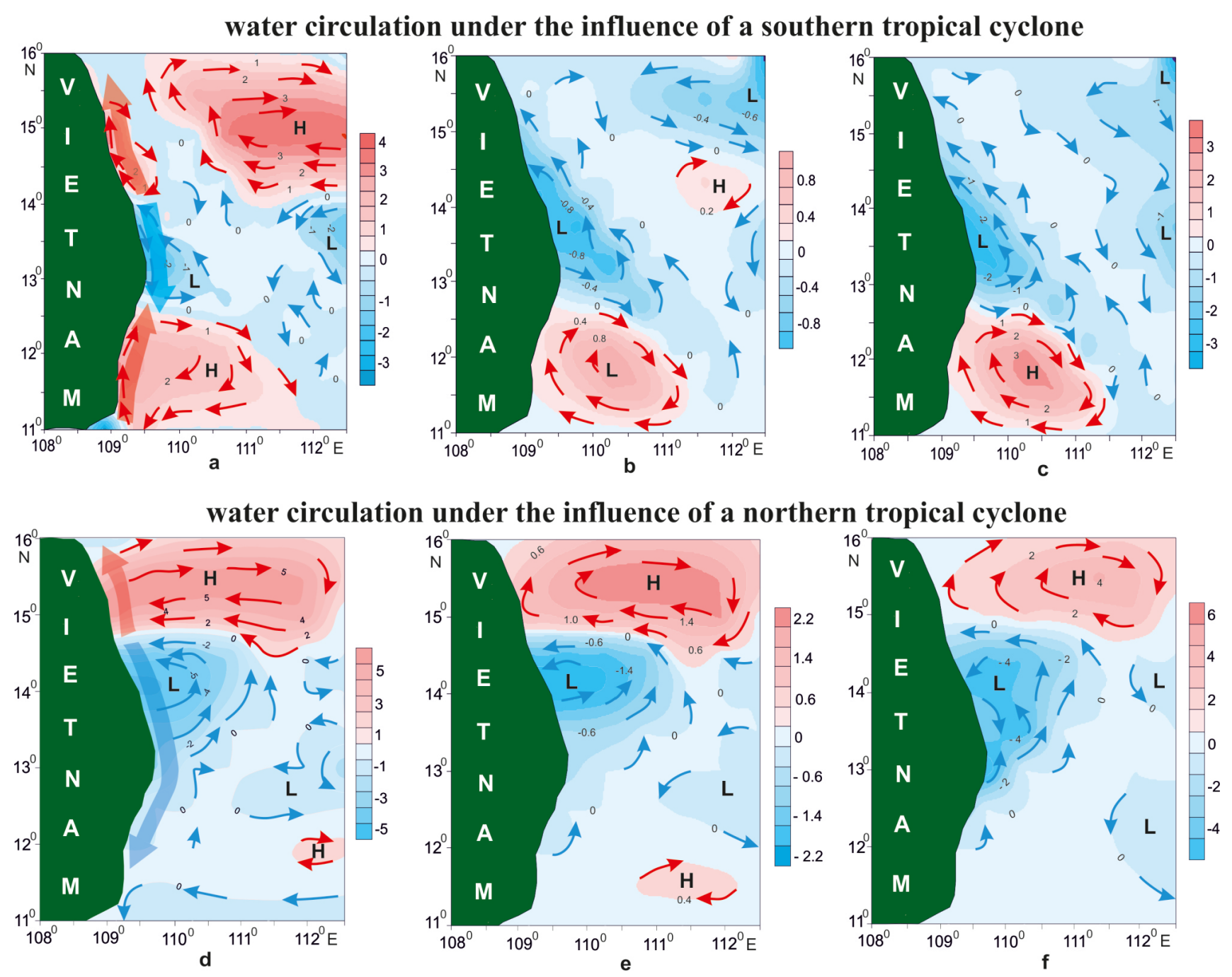

Figure 5. Water circulation under the influence of the southern atmospheric tropical cyclone (a, b, c), and the northern atmospheric tropical cyclone (d, e, f) in the South China Sea for the period 04.21-06.05.1999. a, d - surface layer, $\psi=1 \times 10^{7} \mathrm{~cm}^{3} / \mathrm{s}$; b, e - layer $0-200 \mathrm{~m}, \psi=1 \times 10^{11} \mathrm{~cm}^{3} / \mathrm{s} ; \mathrm{c}, \mathrm{f}$ - from the surface to the bottom (full flow), $\psi=1 \mathrm{~Sv}=1 \times 10^{6} \mathrm{~m}^{3} / \mathrm{s}=1 \times 10^{12} \mathrm{~cm}^{3} / \mathrm{s}, \psi$ - current function; $L$ - cyclone; $H$ anticyclone.

zons does not lose its shape. In the southern part of the region, against the general background of weak cyclonic water circulation, only a small anticyclonic vortex is modeled, which can be traced only in the upper layers (see Figure 5d, e). The cyclonic cycle expands with depth and changes its shape. As can be seen, in this location of the atmospheric cyclone, the formation of hydrodynamic structures in the studied area occurs with the same regularity as in the first case, when the atmospheric cyclone was located in the south of the South China Sea.

Thus, depending on the location of tropical cy- clones in the south or the north of the study area, hydrodynamic processes are also intensified in the south or the north, as a result of which a summer regime of water transfer (from south to north) is established here. In the rest of the study area, the winter regime of water transfer (from north to south) remains.

In our opinion, this comparison showed that different spatial positions of atmospheric tropical cyclones cause the formation of different hydrodynamic structures in the study area. Moreover, the activity of hydrodynamic rearrangements in its dif- 
ferent parts depends on the distance from the active tropical cyclone.

\section{Conclusion}

The comparative analysis described above led to the following conclusions:

1. in all the atmospheric and hydrodynamic processes considered by us, the Vietnamese Current, as a single and unbroken stream of water masses, does not exist. Instead, several hydrodynamic cycles are formed here;

2. within the study area revealed the spatial dependence of the intensification and reconstruction of hydrodynamic processes on the distance from the active tropical cyclone. The closer the tropical cyclone is to the study area, the more powerful the anticyclonic structures of the nearest district of the water area: the processes of upwelling and active mixing of water begins;

3. the direction of transfer of water masses (summer or winter regimes) in the zone of coastal water circulation depends on the position of tropical cyclones over the water area of the South China Sea: if the tropical cyclone is located above the southern (northern) part of the South China Sea, then the summer water regime is established in the southern (northern) part of the studied water area.

Acknowledgments. This work was supported by the Russian-Vietnamese grant No. VANT19-020 in the framework of the Basic Research Program of the Far Eastern Branch of the Russian Academy of Sciences for 2018-2020.

\section{References}

Barabashkina, A. P., E. A. Leskova (1968), Studies of typhoons overlooking the Sea of Japan and the Primorsky Territory, Trudy of Far Eastern Research Hydrometeorological Institute, 3, 3-33. (in Russian)

Dang, K. M. (1974), Oceanological conditions of the South China Sea, Marine Collection, 4 p. 91-93, Naval Publishing House, Leningrad. (in Russian)
Dobryshman, E. M. (1980), Dynamics of the Equatorial Atmosphere, 288 pp. Gidrometeoizdat, Leningrad. (in Russian)

Domysheva, A. S. (2019), The influence and consequences of tropical cyclones on the coastal territories of the Northern Hemisphere, Young Scientist, Kazan, 20, 50-52. (in Russian)

Felsenbaum, A. I. (1970), Dynamics of sea currents, Results of science. Hydromechanics p. 97-338, VINITI, Moscow. (in Russian)

Kuzin, V. S. (1999), The origin, movement, evolution of typhoons and their prediction by synopticstatistical methods, Dissertation of the Dr. Geogr. Sci., p. 123, Far Eastern State University, Vladivostok. (in Russian)

Kuznetsov, A. A. (1997), Physics of the Natural Environment, Tutorial, Part 2: "World Ocean", 96 pp. Moscow State University of Geodesy and Cartography, Moscow. (in Russian)

Liu, Qinyu, Arata Kaneko, Su Jilan (2008), Recent progress in studies of the South China Sea circulation, J. Oceanogr., 64, 753-762, Crossref

Mamedov, E. S., N. I. Pavlov (1974), Typhoons, 137 pp. Gidrometeoizdat, Leningrad. (in Russian)

Morimoto, Akihiko, Koichi Yoshimoto, Tetsuo Yanagi (2000), Characteristics of sea surface circulation and eddy field in the South China Sea revealed by satellite altimetric data, J. Oceanogr., 56, 331-344, Crossref

Nguyen, Z. T. (1990), Water circulation of the South China Sea in the winter and summer seasons, Dissertation of the Dr. Geogr. Sci., p. 177, Il'ichev Pacific Oceanological Institute, FEBRAS, Vladivostok. (in Russian)

Polyakova, A. M., G. A. Vlasova, A. S. Vasiliev (2002), The Influence of the Atmosphere on the Underlying Surface and Hydrodynamic Processes of the Bering Sea, 202 pp. Dal'nauka, Vladivostok. (in Russian)

Polyakova, A. M. (2011), Classification of atmospheric processes over the South China Sea, Russian Meteorology and Hydrology, 36, 294-298, Crossref Qu, T. (2000), Upper-layer circulation in the South China Sea, J. Phys. Oceanogr., 30, 1450-1460, Crossref

Shapiro, N. B. (1965), Analytical study of the relationship between wind and current in the equatorial ocean zone, Doklady of the Academy of Sciences of the USSR, 164, No. 2, 319-322. (in Russian)

Siripong, A. (1985), Dynamics of the thermal structure of the upper layer and surface circulation of the South China Sea, Comprehensive Global Monitoring of the Oceans. Proceedings of the I Int. USSR Symposium. Tallinn, 1983, Vol. 3 p. 150-178, Hydrometeoizdat, Leningrad. (in Russian)

Tang, DanLing, Hiroshi Kawamura, et al. (2004), Offshore phytoplankton biomass increase and its oceanographic causes in the South China Sea, Marine Ecology Progress Series, 268, 31-41, Crossref 
Uda, M., T. Nakao (1973), Water masses and currents in the South China Sea and their seasonal change, The Kuroshio III. Proceeding of the third CSK (Cooperative Study of the Kuroshio), Symposium p. 161-188, CSK, Thailand, Bangkok.

Vasiliev, A. S. (2001), Adaptive Learning System of Forecasting Classes of Natural Processes. Part 1, 136 pp. Gidrometeoizdat, St. Petersburg. (in Russian)

Vasiliev, A. S., G. A. Vlasova, A. M. Polyakova (2011), A program for calculating water circulation of the South China Sea under the influence of various types of atmospheric processes. Certificate of state registration of computer programs No. 2011615257, V. I. Il'ichev Pacific Oceanological Institute FEBRAS, Vladivostok. (in Russian)

Vlasova, G. A., A. S. Vasiliev, G. V. Shevchenko (2008), Spatio-Temporal Variability of the Structure and Dynamics of the Waters of the Sea of Okhotsk, 359 pp. Nauka, Moscow. (in Russian)

Vlasova, G. A., Bui Hong Long, S. N. Taranova, et al. (2010), Background data on the South China sea, Preprint, 98, 57 pp. V. I. Il'ichev Pacific Oceanological Institute FEBRAS, Vladivostok. (in Russian)

Vlasova, G. A., A. M. Polyakova, M. N. Demenok (2011), The influence of the variability of surface water circulation in the South China Sea on the AsiaPacific region in winter, Vestnik FEB RAS, Vladivostok, 3, 104-111. (in Russian)

Vlasova, Galina A., Nguen Ba Xuan, Bui Hong Long (2012), Circulation of Vietnamese waters under "weak pressure field" in the spring of 1999, Proceeding of the International Conference on "Bien Dong 2012": 90 years of Marine Science in Vietnamese and Adjacent waters, Vol. 2 p. 73-80, Na Trang, Vietnam. (in English and Vietnamese, ISBN 978604-913-172-1)

Vlasova, G. A., Nguyen Ba Xuan, Bui Hong Long (2013a), The influence of synoptic processes on the vietnamese current (the South China Sea) Dynamics during the Winter-Summer 1999 transition period, Russian Meteorology and Hydrology, 38, 239-247, Crossref

Vlasova, G. A., Nguyen Ba Xuan, Bui Hong Long (2013b), Influence of tropical cyclones on the Vietnamese current dynamics in the spring 1999, Proceeding of the Second Scientific Conference on Marine Geology p. 1075-1086, Institute of Marine Geology and Geophysics, Vietnam Academy of Sciences and Technologies, Vietnam, Hanoi-Halong. (in English and Vietnamese)

Vlasova, G. A., Nguyen Ba Xuan, M. N. Demenok (2016a), Water Circulation of the South China Sea in the Vietnamese Current Zone under the Conditions of the Southern Tropical Cyclone in the Spring of 1999: Results of Numerical Simulation, Fundamental'naya i Prikladnaya Gidrofizika, 9, No. 4, 25-34. (in Russian)

Vlasova, G. A., M. N. Demenok, et al. (2016b), The Role of Atmospheric Circulation in Spatial and Temporal Variability in the Structure of Currents in the Western South China Sea, Izvestiya, Atmospheric and Oceanic Physics, 52, No. 3, 317-327, Crossref

Vlasova, G. A., Nguyen Ba Xuan, M. N. Demenok (2018), Water circulation in the zone of the Vietnam Current in the conditions of a low-gradient baric field (South China Sea), Uchenye Zapiski of Russian State Hydrometeorological University, 52, 49-60. (in Russian)

Wyrtki, K. (1961), Scientific Results of Marine Investigation of the South China Sea and Gulf of Thailand, NAGA, Report 2, 195 pp. The University of California, Scripps Institution of Oceanography, La Jolla, California, California, US.

Yuan, Y., G. Liao, X. Xu (2007), Three dimensional diagnostic modeling study of the South China sea circulation before onset of summer monsoon in 1998, J. Oceanogr., 63, No. 1, 77-100, Crossref

Zhao, X., H. Pang, X. Li, P. Song (2008), Abnormal incident analysis of tropical cyclones influencing South China Sea in 1997, J. Tropic. Oceanogr., 27, No. 1, 11-15.

\section{Corresponding author:}

Galina Vlasova, Il'ichev Pacific Oceanological Institute, Far Eastern Branch of RAS, 43 Baltiiskaya, 690041 Vladivostok, Russia. (gavlasova@mail.ru) 